\title{
Activin is an essential early mesenchymal signal in tooth development that is required for patteming of the murine dentition
}

\author{
Christine A. Ferguson, Abigail S. Tucker, Lars Christensen, Anthony L. Lau, ${ }^{1,3}$ \\ Martin M. Matzuk, ${ }^{1,2,3}$ and Paul T. Sharpe ${ }^{4}$ \\ Department of Craniofacial Development, Guy's Hospital, London Bridge, London, SE1 9RT, UK; Departments \\ of ${ }^{1}$ Pathology and Cell Biology, ${ }^{2} \mathrm{M}$ olecular and Human Genetics, and ${ }^{3}$ Program in Developmental Biology, Baylor College \\ of Medicine, Houston, Texas 77030 USA
}

\begin{abstract}
Development of the mammalian tooth has been intensively studied as a model system for epithelial/ mesenchymal interactions during organogenesis, and progress has been made in identifying key molecules involved in this signaling. We show that activin $\beta A$ is expressed in presumptive tooth-germ mesenchyme and is thus a candidate for a signaling molecule in tooth development. Analysis of tooth development in activin BA mutant embryos shows that incisor and mandibular molar teeth fail to develop beyond the bud stage Activin $\beta A$ is thus an essential component of tooth development. Development of maxillary molars, however, is unaffected in the mutants. Using tissue recombination experiments we show that activin is required in the mesenchyme prior to bud formation and that although activin signaling from mesenchyme to epithelium takes place, mutant epithelium retains its ability to support tooth development. Implantation of beads soaked in activin A, into developing mandibles, is able to completely rescue tooth development from E11.5, but not E12.5 or E13.5, confirming that activin is an early, essential mesenchyme signal required before tooth bud formation. Normal development of maxillary molars in the absence of activin shows a position specific role for this pathway in development of dentition. Functional redundancy with activin B or other TGF $\beta$ family members that bind to activin receptors cannot explain development of maxillary molars in the mutants since the activin-signaling pathway appears not to be active in these tooth germs. The early requirement for activin signaling in the mesenchyme in incisor and mandibular molar tooth germs must be caried-out in maxillary molar mesenchyme by other independent signaling pathways.
\end{abstract}

[Key Words: Activin; tooth; follistatin; patterning]

Received January 22, 1998; revised version accepted May 28, 1998.

Development of the mammalian tooth has been intensively studied as a model system for epithelial/mesenchymal interactions during organogenesis (for review, see Thesleff et al. 1995; Thesleff and Sharpe 1997). Reciprocal epithelial-mesenchymal signaling has been shown to be involved at different stages of tooth development. Initiation of tooth germs has been shown to require epithelial signals, epithelial cell differentiation in tooth buds requires mesenchymal signals and signals between epithelial and mesenchymal cells are required for differentiation of ameloblasts and odontoblasts at later stages. Recently, progress has been made in identifying key molecules involved in these signaling pathways at different stages of early tooth development. Thus, the transcription factors, MSX1 and LEF1 have been shown to be required for tooth devel opment to proceed beyond the epithelial bud stage with BM P4 being an

${ }^{4}$ Corresponding author.

E-MAIL psharpe@hgmp.mrc.ac.uk; FAX 1719552704. important component of the signal ing pathway (Satokata and Maas 1994; van Genderen et al. 1994; Chen et al. 1996). Signaling molecules belonging to the TGF $\beta$, WNT, FGF, and $\mathrm{HH}$ families are also all expressed in cell-restricted fashions during different stages of tooth development and may play key roles in setting up patterning and initiating tooth development (Vainio et al. 1993; Heikinheimo et al. 1994; Bitgood and McMahon 1995; Iseki et al. 1996). In this paper we focus on the role of activin, a member of the TGF $\beta$ family of growth factors.

Activin proteins are produced from two gene-products, activin $\beta A$ and activin $\beta B$ which dimerize to form activin $A(\beta A: \beta B)$, activin $B(\beta B: \beta B)$ and activin $A B(\beta A: \beta B)$. The closely rel ated inhibins, inhibin $A$ and inhibin $B$, are dimers consisting of an activin $\beta A$ or $\beta B$ subunit linked to an inhibin-specific $\alpha$ subunit (Val e et al. 1990; Roberts et al. 1991; Roberts and Barth 1994). Activin has been shown to have an essential role in mesoderm and neural induction in Xenopus development. Activin protein is 
present in the egg and is later expressed zygotically in the Spemann's organizer (D ohrmann et al . 1993). M icroinjection of activin mRNA causes partial axis duplication (Thomsen et al. 1990). Furthermore, treatment of prospective ectodermal tissue with activin causes the induction of mesodermal cell types (Asashima et al. 1990). Different concentrations of activin specify at least five different cell types, including the most dorsal mesodermal cell type, notochord (Green and Smith 1990; Green et al. 1992). The role of activin in early Xenopus development has also been demonstrated using over-expression of truncated activin receptors. Inhibition of activin signaling using these receptors causes a loss of mesodermal derivatives and an increase in neural differentiation (Hemmati-Brivanlou and Melton 1992, 1994). Recently, a novel design of truncated receptor which, unlike previous designs, specifically inhibits activin but does not affect Vgl or any other known mesoderm inducer, was al so reported to disrupt mesoderm formation, thus confirming earlier findings (Dyson and Gurdon 1997).

Targeted mutation of either activin $\beta \mathrm{A}$ or $\beta \mathrm{B}$ genes or both genes together does not affect mesoderm development or neural differentiation in mice (Matzuk et al. 1995a), implying either that activin signaling has no obvious role in mesoderm and neural induction in the mouse or that there is functional redundancy with other as yet undiscovered activins, or other TGF $\beta$ family members. N odal, a member of the TGF $\beta$ family has already been shown to be required for correct mesoderm formation in the mouse (Zhou et al. 1993; Conlon et al. 1994). A third possibility is that activin A produced in the maternally derived decidua is able to rescue embryonic development. However, the lack of defects in the mesoderm in activin receptor type II knockouts argues against this (Matzuk et al. 1995b).

We report here that activin $\beta A$ has an essential role in tooth development, being required for development of incisor and mandibular molar tooth germs to progress beyond the bud stage. Development of maxillary molars in activin $\beta A$ mutants is normal, producing normally mineralised teeth at birth. Thus, the essential role for activin in tooth development is restricted to specific teeth, suggesting a role for activin signaling in patterning of the dentition.

Here, we show that mandibular molar tooth development in mutant tissues can be rescued by addition of exogenous activin A into mesenchyme prior to bud formation or by recombination of mutant dental epithelium with wildtype dental mesenchyme. Development cannot, however, be rescued at the bud stage either by exogenous activin or by recombination of wild-type epithelium with mutant mesenchyme. From these experiments, we can conclude that activin A has an essential early role in cell signaling from presumptive tooth-bud mesenchyme at a time when it is believed that signals from the epithelium are essential for tooth development. We further show that the existence of this essential mesenchyme signal is not inconsistent with data showing that oral epithelium is instructive for tooth development at this stage because activin expression requires a signal, identified as FGF8, which is restricted to the oral epithelium to maintain its expression.

activin $\beta A$ is normally expressed in the condensing mesenchyme surrounding the epithelial tooth bud in all developing teeth so the patterning phenotype cannot be easily explained by spatial differences in activin activity. We show here that follistatin is a downstream target of activin signaling and that its expression is down-regulated in the epithelium of all teeth in the mutants, including the maxillary molars, indicating that neither activin $\beta A$ nor follistatin are required for maxillary molar tooth development and suggesting that maxillary molar development involves activin-independent signaling pathways.

\section{Results}

Expression of activin $\beta A$ in early tooth development

Expression of activin $\beta A$ was analyzed in the developing jaws of embryos between days 10.5 and 14.5 of gestation (E10.5-E14.5) using radioactive in situ hybridization. Weak expression could be first detected between E10.5 and E11 in mesenchymal cells of the mandi bular process of the first branchial arch (data not shown). At this stage, no transcripts were detected in the maxillary process of the 1st branchial arch, which is slightly delayed in its development with respect to the mandibular process. However, activin $\beta$ A expression was clearly visible at E11.5 in both the mandible and maxilla in the mesenchymal cells underlying the epithelial thickenings that will give rise to the future molars and incisors (Fig. $1 A, B)$. At later stages activin $\beta A$-expressing cells comprised a distinct band of mesenchymal cells condensing beneath the epithelial tooth buds (Fig. $1 \mathrm{C}-\mathrm{H}$ ). In addition, activin $\beta$ A expression could be detected in the mesenchyme surrounding the nasal epithelium and the palatal shelves (Fig. 1C,D).

Tooth development in activin $\beta A$ and activin $\beta A / \beta B$ double mutants

Frontal sections of newborn activin $\beta A$ mutant mice were compared with those of heterozygous and wild-type littermates (Fig. 2). The sections reveal the absence of both maxillary and mandibular incisors as well as mandibular molars in the mutants, the expected positions of these teeth being occupied by bone (Fig. 2, B,D,F vs. $A, C, E)$. The maxillary molar teeth, however, were present in their correct positions in the mutants and had a normal histological appearance (Fig. 2 E,F). The tooth phenotype in activin $\beta A$ mutants thus represents a patterning abnormal ity, where devel opment of only certain teeth are affected. Patterning of the dentition is al so affected in $D I x 1 / 2$ double mutants that have a reciprocal phenotype of activin $\beta A$ mutant embryos, where only development of maxillary molars is affected (Qiu et al. 1997; Thomas et al. 1997).

To establish whether odontogenesis of incisors and mandibular molars is initiated in the mutants, frontal 


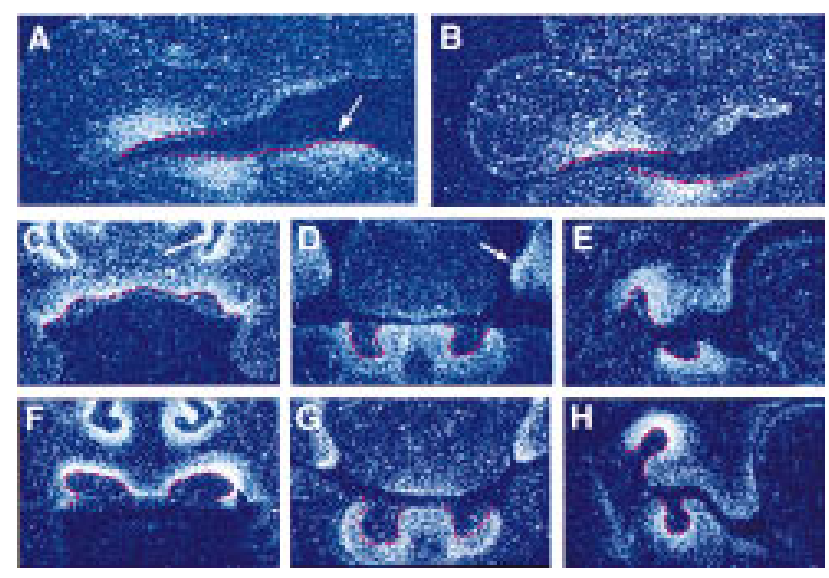

Figure 1. The expression pattern of activin $\beta A$ during early tooth devel opment. Radioactive in situ-hybridization on frontal sections showing activin $\beta A$ expression in the developing jaws of embryos at E11.5 (A,B), E12.5-13 (C-E), and E14.5 (F-H). Tooth germ epithelium is outlined in red. $(A, B)$ Teeth at the epithelial thickening stage of devel opment. The arrow indicates the lower incisor region. (B) A more proximal section than shown in $A$, cut through the molar region. (C-E) Teeth at the early bud stage of development, showing expression in the upper incisors (C), lower incisors (D), and molars (E). The arrow in $\mathrm{C}$ indicates the nasal process; the arrow in $\mathrm{D}$ indicates the palatal shelves. $(\mathrm{F}-\mathrm{H})$ Teeth at the late bud stage of development, showing expression in the upper incisors (F), lower incisors $(G)$, and molars $(\mathrm{H})$.

sections of mutant embryos at E12.5 (early bud stage of tooth development), E13.5 (late bud stage), and E14.5 (cap stage) were examined. Development of maxillary incisors and all mandibular teeth was found to be initiated but arrested at the bud stage, whereas maxillary molar tooth germs were present at the correct stage in al I of the embryos examined (Fig. 3). The mesenchymal component of the mutant teeth appeared to be unaffected at a histol ogical level, since condensations of mesenchymal cells were found to underlie the epithelial buds as in wild-type tooth buds.

To investigate whether activin $\beta \mathrm{B}$ activity might compensate for the loss of activin $\beta A$ within the unaffected upper molars in the mutants, the newborn phenotype of activin $\beta A / \beta B$ double-knockout mice was analyzed. As in the activin $\beta A$ mutants, the maxillary molars were present and had a normal histological appearance (Fig. $2 \mathrm{G}$ ). All other teeth were absent, showing that there is no functional redundancy between the two activins for maxillary molar development.

\section{Rescue of tooth development by exogenous activin}

activin $\beta A$ expression first becomes clearly visible in presumptive tooth mesenchyme at E11.5 and, because tooth development is arrested in the mutants at the bud stage (E13.5), the requirement for activin must be between these times. To pinpoint the time when activin is required, beads soaked in activin A protein were implanted into the mesenchyme of mutant mandible explants at E11.5 and E13.5. In situ hybridization was used
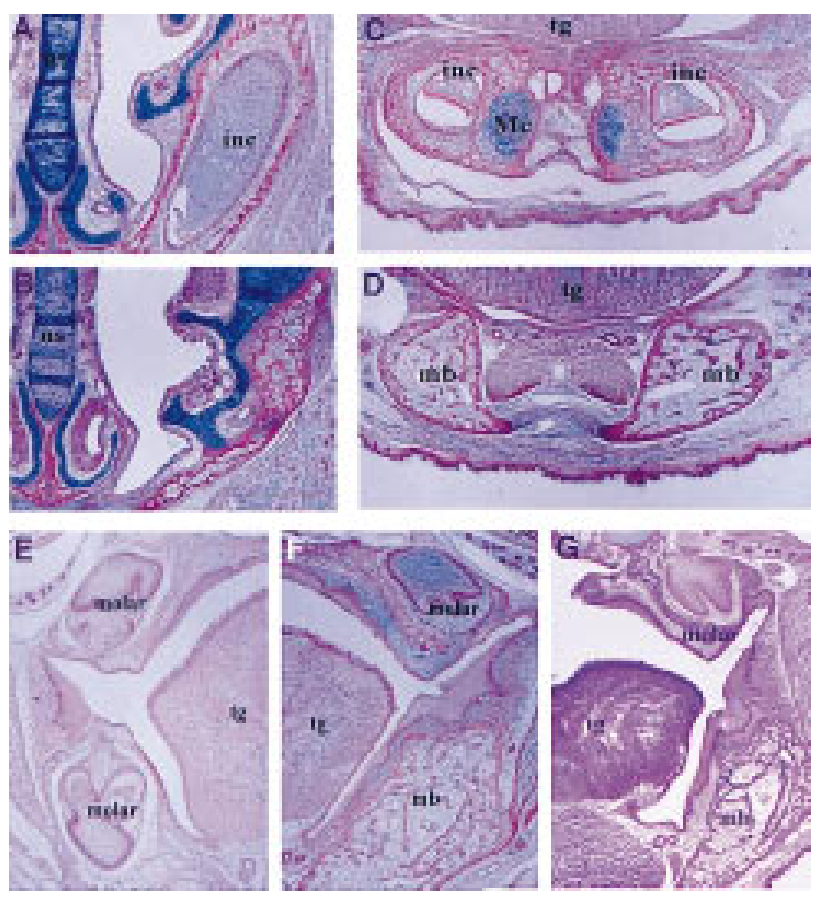

Figure 2. The tooth phenotypes of wild-type, activin $\beta A$ mutant, and activin $\beta \mathrm{A} / \beta \mathrm{B}$ mutant newborn mice. Frontal sections show that upper and lower incisors are present in wild-type mice $(A, C)$, but missing in activin $\beta A$ mutants $(B, D)$. Maxillary and mandibular molars are present in wild-type mice $(E)$; mandibular molars are missing in both the activin $\beta A(F)$ and activin $\beta A / \beta B$ mutants (G). (inc) Incisor; ( $m b$ ) mandibular bone; (Mc) Meckels' cartilage; (ns) nasal septum; (tg) tongue.

to confirm that activin is unable to induce its own expression. Therefore the bead was acting as the only source of activin in these experiments (Fig. 4F,G). Explants were cultured for 24-72 hr and then transplanted into kidney capsules. Table 1 shows the numbers of teeth obtained, and Figure 4, B-E, shows typical histology of the resulting tissue. At E11.5 6 molars were formed from a total of 12 explants with implanted activin beads, whereas at E13.5 no teeth were formed. In-

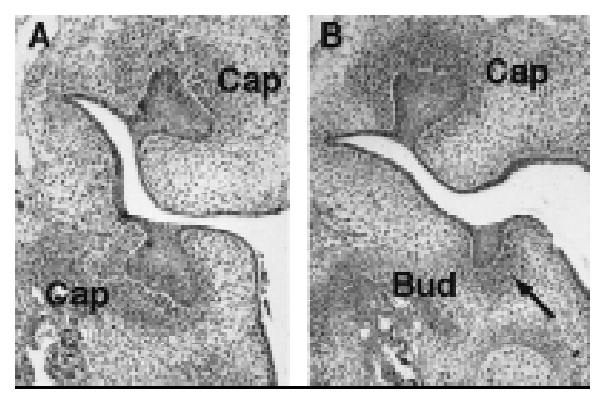

Figure 3. The tooth phenotype of activin $\beta A$ heterozygous and homozygous mutant embryos at E14.5. (A) Frontal sections showing molar tooth germs at the cap stage of development in activin $\beta$ A heterozygotes. (B) In activin $\beta$ A homozygous mutant embryos the upper molars are at the cap stage, whereas the lower molars are arrested at the bud stage. $N$ ote condensation of mesenchyme still occurs around the buds in the mutant (arrow). 
A
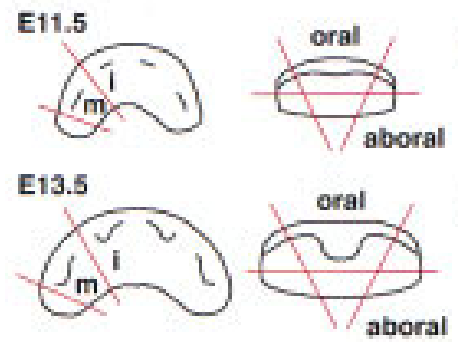

B

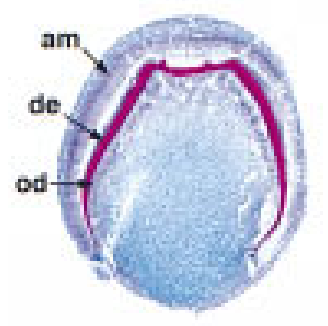

C

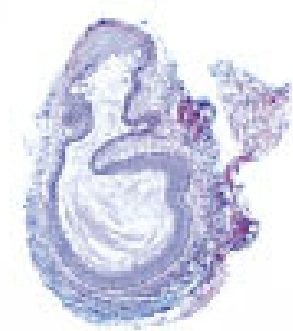

D
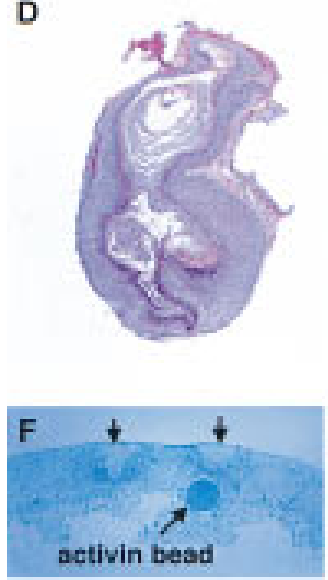

$\mathbf{E}$
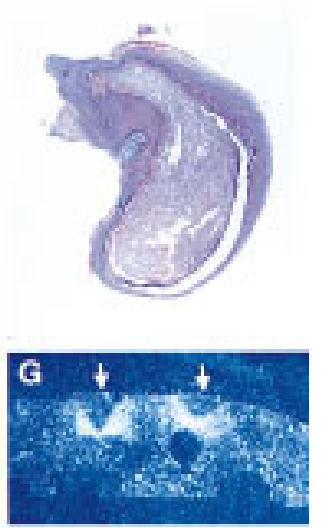

Figure 4. Tooth development in activin $\beta$ A mutant molar primordia treated with exogenous activin A protein at E11.5 and E13.5. (A) Schematic diagram showing procedures involved in the bead rescue experiments. M andibular molar anlagen were dissected away from surrounding oral and aboral tissues. Beads soaked in activin A protein or BSA were embedded in the dental mesenchyme in close proximity to the invaginating dental epithelium. (i) Incisor; (m) molar. (B-E) Representative sections of E11.5 (B,C) and E13.5 (D,E) explants after culture as subrenal grafts. N ote that beads became dissociated from explants during transfer to the kidneys. (B) Fully developed molar resulting from the "rescue" of E11.5 mutant molar tissue cultured in the presence of an activin A bead. Note the cytodifferentiation of odontoblasts (od) secreting dentine (de) and ameloblasts (am). (C) A keratinizing-epithelial cyst arising from E11.5 mutant molar tissue cultured in the presence of a BSA bead. (D) Activin A failed to rescue E13.5 mutant molar anlagen, resulting in keratinizing epithelial cysts. (E) Control E13.5 explants cultured in the presence of BSA beads gave rise to keratinizing epithelial cysts. N ote that the tissues shown in B-E were removed from surrounding al veolar bone before being processed for routine histol ogy. $(F, G)$ Control experiment to show that activin does not induce its own expression in the mesenchyme. Activin beads were added to the mesenchyme of mandible explants at E11.5. After 2 days in culture the explants were fixed, sectioned, and analyzed using radioactive in situ hybridization. (F) Light-field photomicrograph showing the position of the activin bead in the mesenchyme. Incisor tooth buds are marked by arrows. (G) Corresponding dark-field photomicrograph showing expression of activin $\beta A$ beneath incisor buds, but not around the bead.

stead of teeth, the four explants gave rise to four keratinizing epithelial cysts embedded in alveolar bone. The control experiments showed that implanting BSA beads had no effect on the expl ants, the mutant expl ants gi ving rise to cysts and wild-type explants giving rise to teeth (see T able 1). Exogenous activin thus enables completion of tooth organogenesis and terminal cytodifferentiation in mutant mesenchyme when delivered at E11.5 but is

Table 1. Teeth formed in kidney capsules by mutant tooth anlagen following implantation of activin-soaked beads

\begin{tabular}{lcc}
\hline & \multicolumn{2}{c}{ No. of teeth } \\
\cline { 2 - 3 } & E11.5 & E13.5 \\
\hline Mutant molar +activin A bead & $6 / 12$ & $0 / 4$ \\
Mutant molar +BSA bead & $1^{*} / 6$ & $0 / 5$ \\
Wild-type molar +BSA bead & $9 * * / 6$ & $5 / 6$ \\
\hline
\end{tabular}

${ }^{a}(*)$ A small misshapen molar devel oped, reflecting that the mutant phenotype of absent mandibular molars is not quite $100 \%$ penetrant. $(* *)$ The appearance of primary and secondary molars from primary tooth anlagen accounts for the high number of teeth obtained from these explants. unable to rescue at E13.5. These results indicate that activin is required at the epithel ial thickening stage, but before the full bud stage of tooth development.

When performing these experiments we observed that although there is no visible difference between wild-type and mutant embryos in the appearance of the epithelial thickenings at E11.5, there is a clear difference in morphology at E13.5. At this stage, the depth of the epithelial invaginations that form a bud is greatly reduced in the mutant compared to those in wild-type embryos (data not shown). This suggests that the tooth defect in the mutants is present by E13.5 and therefore too late to be rescued. To determine whether there was any degree of rescue on addition of activin beads at E12.5, beads were implanted into mutant explants at E12.5 which were then cultured for 6 days and sectioned. Of the 12 mutant tooth primordia (incisors and molars) examined, which had access to an activin bead, all had tooth germs arrested at the bud stage, whereas tooth primordia in wild-type control cultures all reached the cap stage (Table 2; Fig. 5). These results indicate that rescue of the mutant phenotype is restricted to E11.5, as addition of beads at E12.5 and E13.5 is too late to rescue tooth development. 
Ferguson et al.

Table 2. Cap stage tooth germs observed following implantation of activin or control BSA beads

\begin{tabular}{llc}
\hline & \multicolumn{2}{c}{ N o. of tooth germs } \\
\cline { 2 - 3 } & \multicolumn{1}{c}{$+1+$} & $10 / 12$ \\
\hline + Activin bead & $0 / 12$ & $7 / 8$ \\
+ BSA bead & $0 / 4$ & 7 \\
\hline
\end{tabular}

Implantation at E12.5 and culture for 6 days.

Tooth development is dependent on activin signaling within the dental mesenchyme

Because exogenous activin could not rescue tooth development at E12.5 and E13.5 this meant that the essential activin signaling identified at E11.5 must be inducing changes that are required for progression beyond the bud stage. To determine which tissue was being targeted by the activin signal, epithelial-mesenchymal recombinations were carried out between mutant and wild-type tissues. Mandibular molar region oral epithelium was removed and recombined with mesenchyme from the same region at E13.5. Mutant epithelium was recombined with wild-type mesenchyme and vice versa, and the explants cultured for 24-48 hr before being transplanted under kidney capsules. Table 3 shows the numbers of teeth obtained and Figure 6 shows typical morphology. The combination of wild-type mesenchyme with mutant epithelium resulted in eight morphologically normal teeth from nine explants. Wild-type epithelium with mutant mesenchyme, however, produced keratinizing epithelial cysts, with the exception of one case (see Table 3). The ability of mutant epithelium to support tooth development with wild-type mesenchyme shows that the early activin signal is not required to induce essential changes in the epithelium and that it is the mesenchyme in this recombination that is instructive for tooth development. This was supported by the reverse recombination where wild-type epithelium, which would have received activin signals by E13.5, was unable to support tooth development with mutant mesenchyme.

\section{Regulation of activin $\beta A$ expression}

Recombination experiments carried out by several dif- ferent groups have established that between E10.5 and E12, tooth development can only be initiated by oral epithel i um (Kollar and Baird 1969; M ina and Kollar 1987; Lumsden 1988). The existence of an essential mesenchymal signal at this time therefore appears inconsistent with this data. To resolve this we investigated the expression of activin $\beta A$ in the absence of epithelium by culturing mandibles explanted at E11.5 for 1-2 days with the epithelium removed. Removal of epithelium resulted in loss of activin $\beta A$ expression indicating that signals from the epitheli um are required to maintain expression (Fig. 7C,D). A likely candidate for such an epithelial signal is FGF8, which is expressed in oral epithelium between E9 and E13 (Heikinheimo et al. 1994; Crossley and Martin 1995). In Figure 7, A and B, consecutive serial sections of an E11.5 embryo show the expression of Fgf8 in the epithelium and activin $\beta A$ expression in the adjacent underlying mesenchyme. Thus, the coexpression of Fgf8 and activin $\beta A$ at this time is consistent with FGF8 being a candidate molecule involved in the regulation of activin $\beta A$. The ability of exogenous FGF8 to maintain activin $\beta A$ expression was therefore assayed by impl anting beads into mesenchyme explants without epithelium and culturing for 1 day. In situ hybri di zation reveal ed activin $\beta A$ expression around the FGF8 beads but not around control BSA beads, indicating that FGF8 secreted from the epithelium is a likely endogenous signal for maintenance of activin $\beta A$ expression (Fig. 7E,F). The requirement for activin as an essential early mesenchymal signal is thus consistent with the instructive role of oral epithelium for tooth germ initiation at this stage, as signals from the epithel ium are required to maintain activin expression in the mesenchyme.

Recently, N eubüser et al. (1997) showed that antagonistic interactions between FGF8 and BMP4 serve to regulate the expression of Pax9, which encodes a member of the family of pai red-box-containing transcription factors and is expressed in the odontogenic mesenchyme from $\sim$ E10. Given the similar expression patterns of activin $\beta A$ and Pax9 (e.g., cf. Figs. $1 E$ and $8 D$, which are consecutive sections from a wild-type embryo at E12.5E13), we were prompted to investigate whether BMP4 had any effect on activin $\beta A$ expression. The action of BMP4 on activin $\beta A$ expression in E11.5 explants was tested in three ways: (1) To test whether BMP4 has an inhibitory action, BM P4 beads were implanted into in-
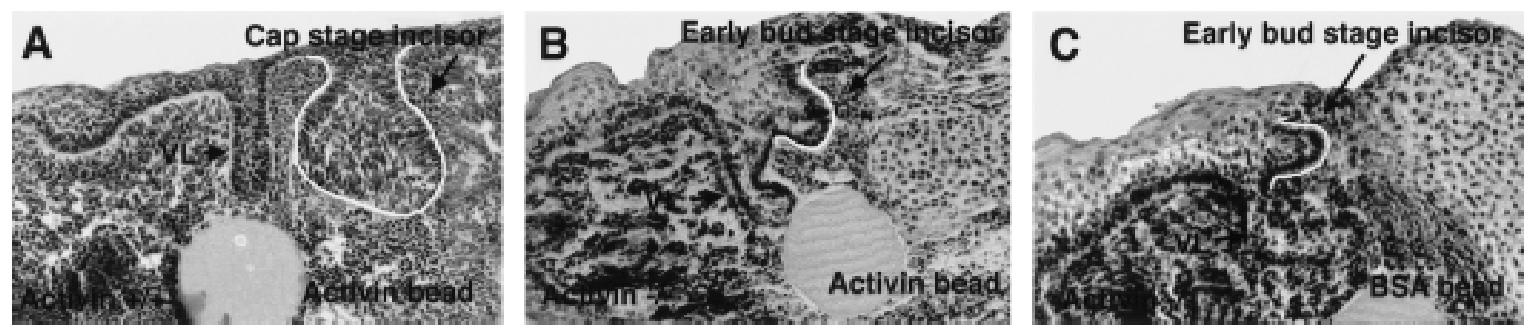

Figure 5. Activin is unable to rescue the tooth development when added to mutant tooth primordia at E12.5. (A) Representative section showing a cap stage incisor in a wild-type explant after culture in the presence of an activin A-loaded bead. (B,C) Representative sections of bud stage incisors in mutant explants after 6 days of culture in the presence of activin A beads (B) and BSA beads (C). Tooth germ epithelium is outlined in white. (VL) Vestibular Iamina. 
Table 3. Teeth formed in kidney capsules after recombination of E13.5 dental epithelium and mesenchyme

Wild-type epithelium

$11 / 10$

Wild-type mesenchyme

Mutant epithelium

$8 / 9$

Wild-type mesenchyme

Wild-type epithelium

Mutant mesenchyme

Mutant epithelium

Mutant mesenchyme

$1 * / 9$

$0 / 2$

(*) The mutant phenotype is not $100 \%$ penetrant, which was confirmed by control cultures. The incisors of the mice were cultured intact and then transferred to kidney capsules as control cultures. Five epithelial cysts and one tiny, underdevel oped incisor were retrieved from the five pairs of mutant incisors explanted.

tact mandibles; (2) to test whether BMP4 could inhibit the maintenance activity of FGF8, BM P4 beads were implanted alongside FGF8 beads into mandible explants with epithelium removed; and (3) to test whether BM P-4 can maintain activin $\beta A$ expression, BMP4 beads were placed on one-half of mandible explants with epithelium removed and as a control and PBS beads were placed on the other half. The explants were cultured for a day and then activin $\beta A$ expression was analyzed using in situ hybridization. Our results indicate that BM P4 is not involved in the regulation of activin $\beta A$ expression: BM P4 could neither maintain or inhibit activin $\beta A$ expression (data not shown) nor inhibit the maintenance activity of FGF8 (Fig. 7G,H).

\section{Gene expression in activin $\beta A$ mutant teeth}

To identify genes downstream of activin signaling in tooth development, the expression of well-characterized mesenchymal and epithelial marker genes was examined in mutant embryo teeth. The expression patterns in mutant mandi bul ar molars were compared with those in the normal maxillary molar tooth germs. Expression in the mutant incisors was compared with expression in incisors of wild-type or heterozygous littermates (Fig. 8). Radioactive in situ hybridization was performed on wildtype, heterozygous, and homozygous mutant embryos up to the bud stage. The expression patterns of genes examined included Barx1, Msx1, DIx2, Pax9, Gli3, Lef1, syndecan-1, Tgf $\beta 1$, Tgf $\beta 3, \mathrm{Bmp} 4, \mathrm{Bmp} 7$, Sonic hedgehog (Shh), CD44, and OtIx2.

In wild-type teeth at the bud stage, Barx 1 gene expression is restricted to the molar region of the mandible and maxilla but is present in a broad field of neural crest derived mesenchymal cells rather than being restricted to dental mesenchyme (Fig. 8A; Tissier-Seta et al . 1995). Msx1, Lef1, and Bmp4 are expressed in the dental mesenchyme (i.e., the condensing mesenchymal cells associated with invaginating incisor and molar epithelial tooth buds) in response to epithelial signaling (Fig. 8B,F,J; Mackenzie et al. 1991; Vainio et al. 1993; Kratochwil et al. 1996). It is thought that these genes are then involved in reciprocal signaling from mesenchyme to epithelium, which is required for epithelial cell differentiation including the formation of the enamel knot. DIx2 expression is restricted to mesenchymal cells immediately surrounding the epithelial bud, but is also present in the dental epithelium on the buccal side of the buds (Fig. 8C; Thomas et al. 1995; Qui et al. 1997). Pax9 is expressed in early tooth mesenchyme prior to bud formation and subsequently in condensing mesenchyme at the bud stage (Fig. 8D; Neubüser et al. 1997). Gli3 is expressed in the mesenchyme from E10.5. At the bud and cap stage Gli3 expression is slightly more localized than Pax9 expression, and is restricted to the dental papilla and dental follicle (Fig. 8E; Hardcastle and Sharpe 1998). Syndecan1 , a cell surface heparin-sulfate proteoglycan is transiently expressed in the dental mesenchyme and is thought to regulate dental mesenchymal cell condensati on beneath the invaginating dental epithelium (Fig. 8G; Thesleff et al. 1996). Tgf $\beta 1$ is found in the dental mesenchyme and weakly in the epithelium of the incisors and only appears in the molars in the dental epithelium at the cap stage (Fig. 8H; Vaahtokari et al. 1991). Tgf $\beta 3$ expression is widespread in the mesenchyme of the face but, interestingly, its expression appears to be excluded from the condensin mesenchymal cells immeadiately adjacent to the epithelial buds of incisors and molars (Fig. 8l; Chai et al. 1994).

Analysis of genes known to be expressed in tooth germ epithelium included Bmp7, Shh, CD44, and O tl x2 genes. In wild-type embryos, Bmp7 is initially expressed in the dental epithelium, but expression shifts to the mesenchyme around the tooth buds from E13.5 ( $\AA$ berg et al. 1997). At E13.5 mesenchymal Bmp7 expression was

A
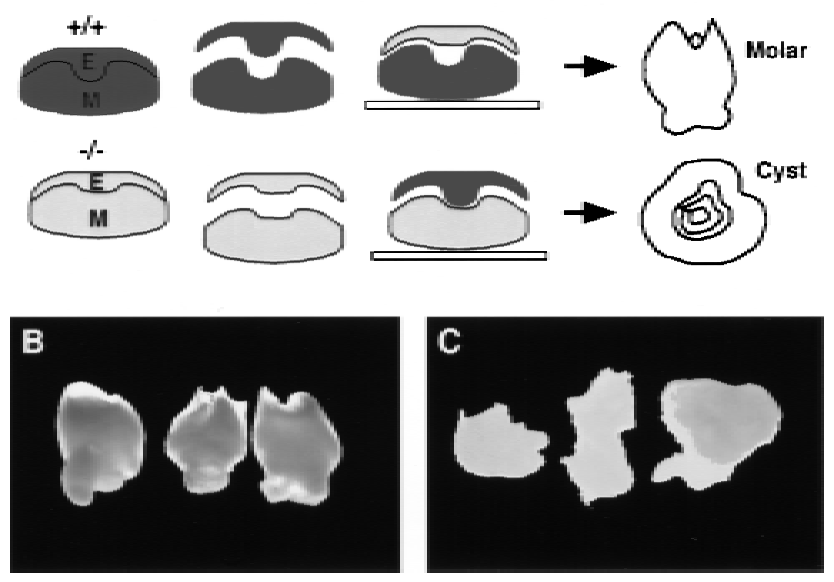

Figure 6. Tooth development in recombinations of dental tissues from wild-type and activin $\beta$ A mutant embryos at E13.5. (A) Schematic diagram illustrating the procedures involved in the tissue recombination experiments. (Black) Wild-type tissue; (white) mutant tissue. (E) Dental epithelium; (M) dental mesenchyme. (B) Representative molars derived from the combination of mutant epithelium with wild-type mesenchyme. (C) Typical cysts derived from the combination of wild-type epithelium with mutant mesenchyme. Histological analysis of these cysts revealed keratinizing stratified epithelium, as shown in Figs. 4C-E. 

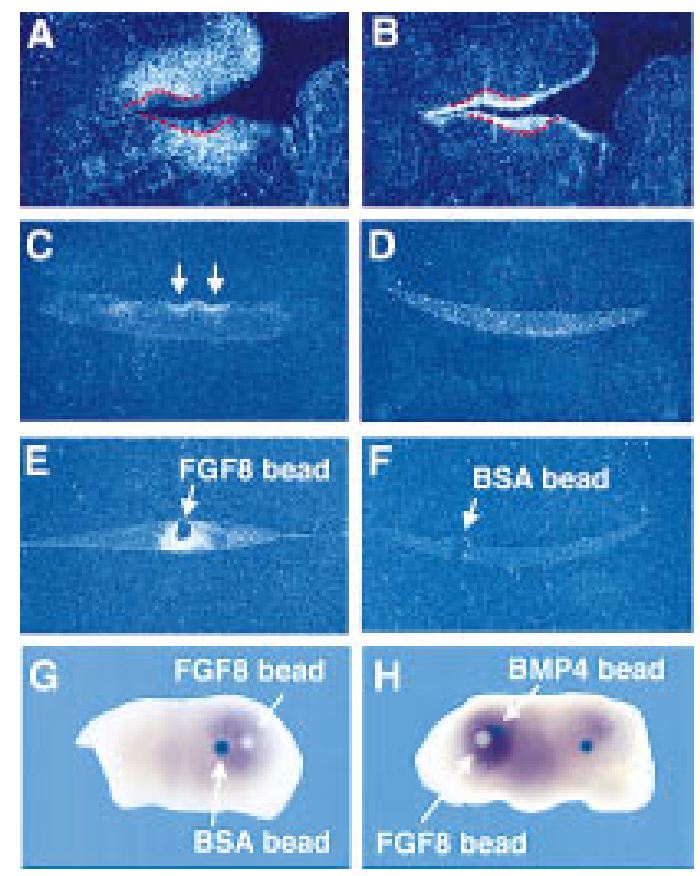

Figure 7. FGF8 is required to maintain expression of activin $\beta A$ expression in the odontogenic mesenchyme. $(A, B)$ Serial frontal sections through the prospective molar region of an E11.5 wild-type showing the complementary expression patterns of activin $\beta A$ in the mesenchyme (A) and Fgf8 in the epithelium (B) on consecutive sections. The tooth germ epithelium is outlined in red. (C,D) activin $\beta A$ expression in E11.5 mandible explants that were cultured for 2 days with (C) and without (D) epithelium. The arrows indicate the positions of incisor buds. (E,F) activin $\beta A$ expression in E11.5 mandible explants that were cultured for 1 day without epithelium but in the presence of implanted FGF8 beads $(E)$ or BSA control beads (F). (G,H) DIG whole-mount in situ hybridization of E11.0 mandibles that were cultured without epithelium but in the presence of beads. (G) FGF8 maintains activin $\beta A$ expression in the mesenchyme. Beads were placed on half of the mandible. $(H)$ BMP4 does not inhibit the maintenance activity of FGF8. The experiment was performed on both halves of the mandible.

found only in the lower incisors, which are the most advanced developmentally at this stage, whereas expression persists in the epithelium of upper incisors amd molars (Fig. 8K). Shh is expressed in the epithelial thickening of early tooth germs and is thought to be an important component of the signals that pass from the epithelium to the underlying mesenchyme at this early stage, inducing gene expression in the mesenchyme and instructing it to begin condensation (Bitgood and M CM ahon 1995; Thesl eff and Sharpe 1997). At later stages, Shh is down-regulated but transcripts reappear in the epithelial cells that constitute the enamel knot, a transient signaling center that arises in the dental epithelium at the late bud stage of tooth development (Fig. 8L; Vaahtokari et al. 1996). CD44 and Otl x2 are expressed more widely in the oral epithelium than Shh (Fig. 8M,N; Wheatley et al. 1993; Mucchielli et al. 1997). CD44 encodes the hyaluronan receptor and $\mathrm{Ot} \times \mathrm{x} 2$ is the murine homolog of the human gene, which when mutated, causes the disease known as Rieger syndrome in which teeth are absent (Semina et al. 1996).

Expression of these genes was found to be normal in activin $\beta A$ mutant tooth buds (Fig. $8 \mathrm{~A}^{\prime}-\mathrm{N}^{\prime}$ ), showing that at the level of transcription, the essential role for activin in tooth development does not involve any of these molecules.

\section{Role of follistatin in tooth devel opment}

Follistatin is an activin-binding protein that has been shown to inhibit the activity of activin (Michel et al. 1993; De Winter et al. 1996). To assess whether follistatin might interact with activin during early tooth development, the expression patterns of follistatin and activin $\beta A$ were compared on consecutive frontal sections of wild-type embryos by in situ hybridization analysis (cf. Figs. 1, C, D, and E, and 9, A, C, and E). follistatin expression was found in tooth germ epithelial cells immediately adjacent to activin $\beta A$-expressing cells from E11.5 (data not shown). At later stages, follistatin transcripts were found to be restricted to the columnar-shaped cells that form the outermost layer of the epithelial bud, while the central core of epithelial cel Is were foll istatin-negative (Fig. 9 C,E). foll istatin was also found to be expressed in the nasal epithelium, in the epithelium of the palatal shelves, and strongly in the tongue.

Because follistatin is expressed in the tooth epithelium adjacent to and in a complementary pattern to activin $\beta A$ in the tooth mesenchyme, it is a potential target of activin signaling. The expression of follistatin was therefore analyzed in activin $\beta A$ mutant embryos and compared with wild-type embryos. No expression could be detected in the tooth epithel ium of the mutants, or in the nasal epithelium and the palatal shelf epithelium, but normal levels of expression were evident in the tongue where activin is not strongly expressed. Loss of expression in the dental epithelium was found in all teeth (Fig. 9B,D,F), indicating that follistatin is not required for maxillary molar tooth development.

\section{Activation of follistatin expression by activin}

The epithelial expression of follistatin is down-regulated in activin $\beta$ A mutant embryos which indicates that follistatin expression is downstream of activin signaling in developing teeth. In Xenopus, activin has been shown to activate the expression of follistatin in an animal cap assay (Hemmati-Brivanlou et al. 1994). To investigate whether activin can regulate follistatin expression in epithelium derived from the first branchial arch in the mouse, epithelium was isolated from E11.5 mandibles and cultured for $24 \mathrm{hr}$ in the presence of beads soaked in activin A protein. Explants were fixed, sectioned and examined for follistatin expression using in situ hybridization. follistatin was found to be expressed around the activin beads, whereas no expression was detected around BSA control beads (Fig. 10A-E). The induction of 

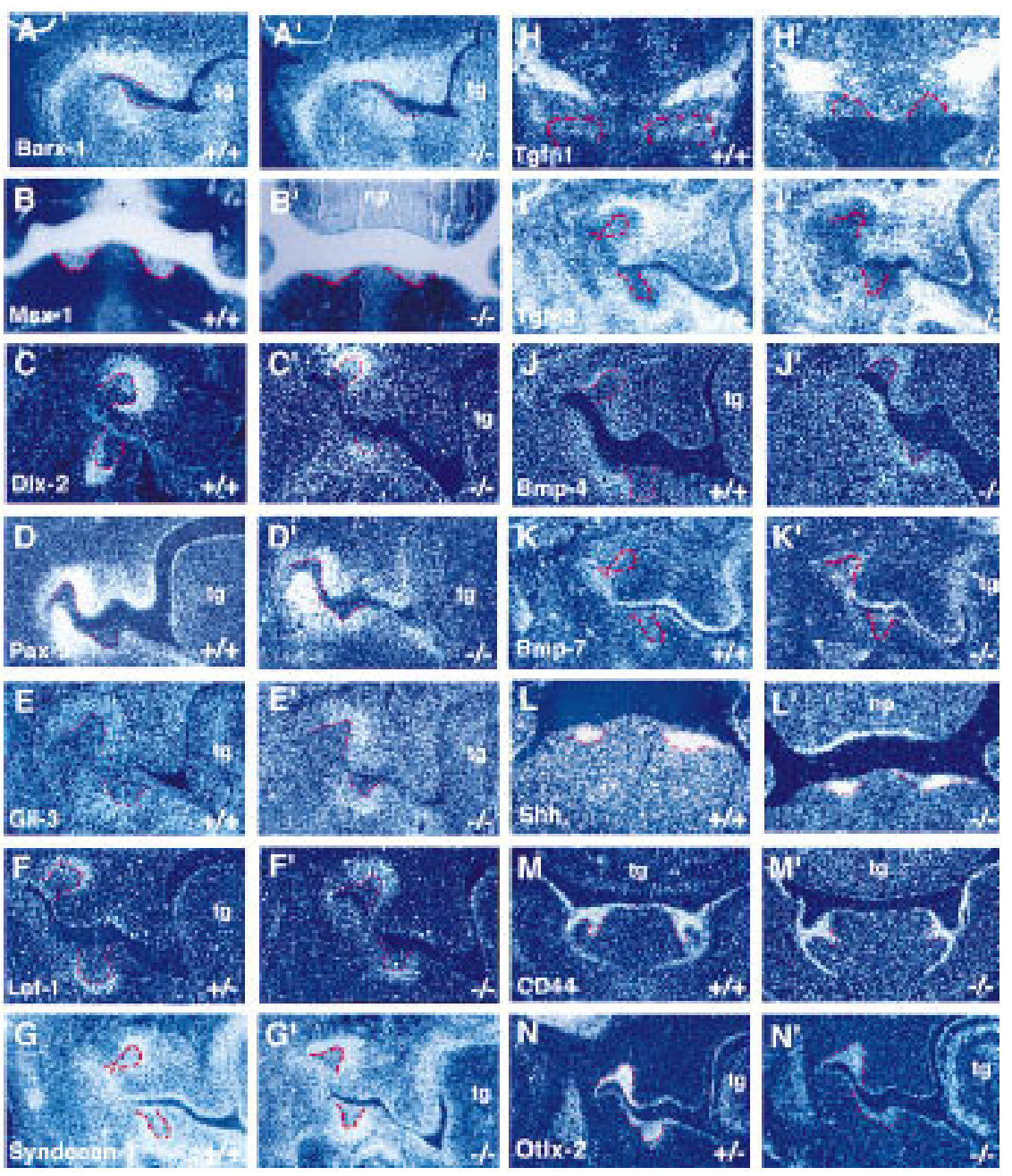

follistatin expression by activin was confirmed as being specific to the epithelium by implanting activin beads into intact mandible explants at E11.5, which showed that follistatin expression was not induced in the mesenchyme (data not shown).

To confirm that activin is an endogenous inducer of follistatin expression we recombined activin $\beta$ A mutant epithelium (follistatin-negative) with wild-type mesenchyme (activin-positive). follistatin expression was found to be induced in the mutant epithelium indicating that activin $A$ is a likely endogenous factor responsible for induction of follistatin gene expression in dental epithelium (Fig. 10F,G). These results demonstrate a mesenchyme to epithelium component to the activin signaling pathway.

\section{Discussion}

We have analyzed the expression patterns of activin $\beta A$ and its antagonist follistatin during the early stages of odontogenesis using radioactive in situ hybridization. We detected weak expression of activin $\beta A$ in presumptive tooth mesenchyme between E10.5 and E11 and strong expression of both activin $\beta A$ and follistatin at velopment.
Figure 8. activin $\beta A$ mutants exhibit normal patterns of expression of mesenchymal and epithelial marker genes in early to late bud stage tooth germs (E12.5E14.5). In situ hybridization on frontal sections show expression of marker genes in oral mesenchyme $\left(A-J^{\prime}\right)$ and epithelium $\left(\mathrm{K}-\mathrm{N}^{\prime}\right)$ of wild-type and activin $\beta \mathrm{A}$ mutant embryos. Tooth germ epithelium is outlined in red. The expression patterns shown were obtained using radioactively labeled probes and dark-field photography except for the images showing Msxl expression $\left(B, B^{\prime}\right)$, which are light-field photomicrographs. The probes used are indicated on the panels. Expression patterns in wild-type embryos are labeled $\mathrm{A}-\mathrm{N}$; the corresponding expression patterns in mutant embryos are labelled $\mathrm{A}^{\prime}-\mathrm{N}^{\prime}$. Molar tooth germs are shown except in $\mathrm{B}^{-\mathrm{B}^{\prime}, \mathrm{L}-}$ $L^{\prime}$, and $M-M^{\prime}$, which show lower incisors and $\mathrm{H}-\mathrm{H}^{\prime}$, which show upper incisors. (np) $\mathrm{N}$ asal process; (tg) tongue.

E11.5 in developing tooth germs. Our results demonstrate earlier expression in the branchial arches than those of Feijen et al. (1994), who mapped the expression of activin $\beta A$ and follistatin in postimplantation mouse embryos between E6.5 and 12.5. They detected the first expression of activin $\beta A$ in the dental mesenchyme at E12.5 but did not report the presence of follistatin transcripts in the tooth epithelium at this stage. Recently, Heikinheimo et al. (1997) reported the expression of activin $\beta A$ and follistatin in the developing molars of embryos between E14 and E19. They suggested a role for the activin-follistatin pathway in the terminal differentiation of odontoblasts. Our results support an earlier and more fundamental role for the activin signal ing pathway in the patterning and morphogenesis stages of tooth de-

The restricted expression of activin $\beta A$ in presumptive tooth mesenchyme and the induction of follistatin in tooth epithelium suggested a role for this signaling pathway in epithelial-mesenchymal interactions known to occur during odontogenesis. We examined tooth development in activin $\beta$ A mutant mice and found that incisor and mandibular molar tooth development was arrested at the bud stage but, surprisingly, that maxillary 


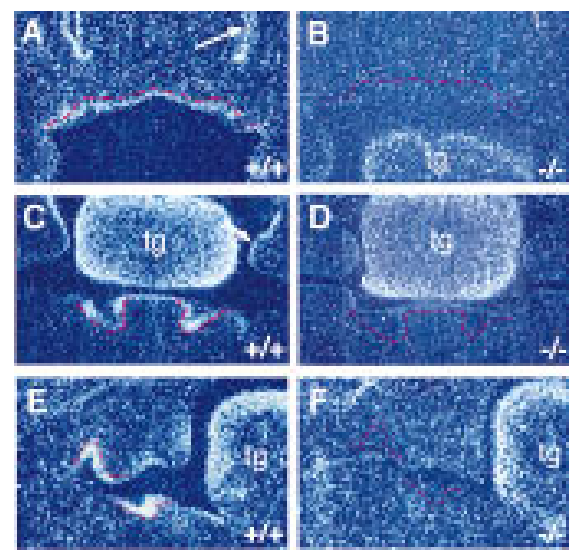

Figure 9. follistatin expression in wild-type and activin $\beta A$ homozygous mutant littermates at E12.5-E13. Tooth germ epithelium is outlined in red. In wild-type littermates, follistatin transcripts are detected in the dental epithelium of the incisor $(A, C)$ and mol ar (E) tooth germs. A djacent frontal sections showing activin $\beta A$ expression at E12.5-E13 are found in Fig. 1 C-E. The arrows in $A$ and $C$ indicate follistatin expression in the nasal epithelium and palatal shelf epithelium, respectively. In the mutants, no follistatin expression is evident in incisor (B,D) or molar $(F)$ tooth germs. N ote that follistatin expression in the tongue (tg) is unaffected in the mutants. Expression of follistatin is also lost in the nasal epithelium and palatal shelf epithelium.

molar teeth developed normally. This phenotype indicates a rol e for activin signaling in patterning of the dentition, being required for development of incisors and mandibular molar teeth but not of maxillary molars. This is the second tooth patterning phenotype to be described in mutant mice. Mutations in DIx1 and DIx2 homeobox genes result in specific arrest of maxillary molar development but incisors and mandibular molars are normal (Thomas et al. 1997). Thus, the tooth phenotype in the activin $\beta A$ mutants is the reciprocal of the DIX1/2 mutant phenotype. These phenotypes differ from those of Msx1, Lef1, and Pax9 mutant mice (Satokata and $M$ aas 1994; Kratochwil et al. 1996; N eubüser et al. 1997), in which all of the teeth are affected. Activin $\beta A$, like DLX 1 and $D L X 2$, appears to have an essential role in the patterning of the dentition.

There are thus two aspects of activin signal ing in tooth development that require explanation: an essential role in development of incisors, and mandibular molars so that their development proceeds beyond the bud stage and a non-essential rol ein devel opment of maxillary molars.

\section{Activin is an early mesenchymal signal}

To address the role of activin signaling in development of incisors and mandibular molars, we used bead rescue and recombination experiments to identify the stage at which activin signaling is critical, and which tissues are responsive to activin signaling. It is well established that tooth devel opment is controlled by interactions between epithelial and mesenchymal cells (for review, see Thesleff and Sharpe 1997). Oral epithelium was originally identified as the source of tooth inducing signals from tissue recombination experiments in which early oral epithelium (taken at stages prior to tooth bud formation) was shown to induce tooth development when recombined with non-oral mesenchyme, as long as the mesenchyme was neural crest-derived. The reciprocal recombination of non-oral epithelium with mandibular arch mesenchyme did not produce teeth (M ina and KolIar 1987; Lumsden 1988). Thus between E10.5 and E11.5,
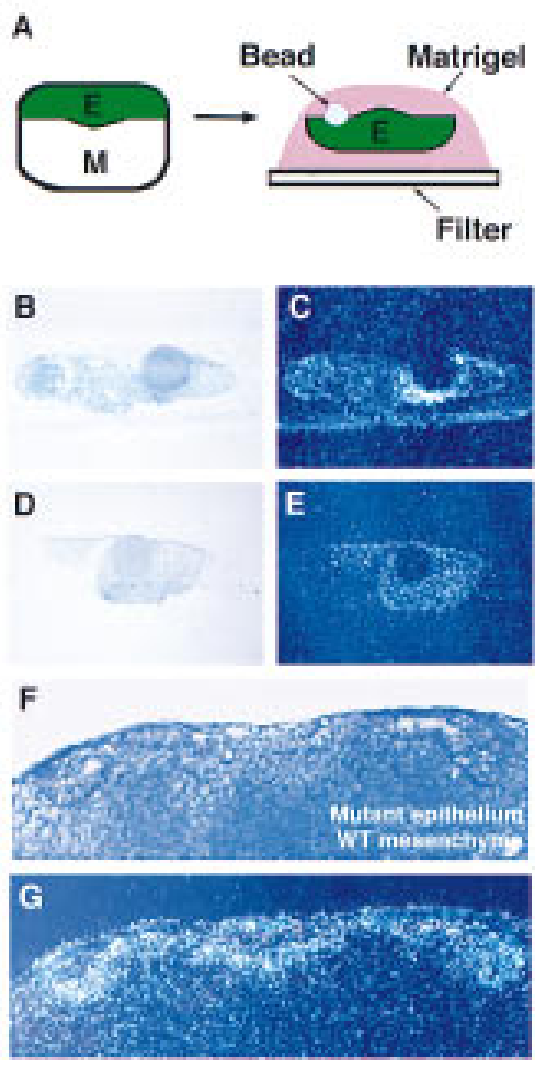

Figure 10. Activin induces follistatin expression in oral epithelium. follistatin expression could be induced by culturing oral epithelium with beads soaked in recombinant activin $A$ protein (A-E) or by supplying mutant oral epithelium with wildtype oral mesenchyme that contains endogenous activin A protein $(F, G)$. (A) Diagram illustrating method of epithelial cultures. (C,E) Radioactive in situ hybridization showing follistatin expression. (B,D) Corresponding light-fiel d photomicrographs of sections. (C) Epithelial culture with activin bead, showing induction of follistatin. (E) Epithelial culture with BSA bead, showing no induction of follistatin. $(F, G)$ Tissue recombinations at E11.5. The combination of oral epithelium derived from activin $\beta A$ mutant embryos (in which follistatin expression is absent) with wild-type oral mesenchyme, resulted in a rescue of follistatin expression in the mutant epithelium. (F) Section through a typical recombination after 3 days in culture. The epithel ium is clearly distinguishable from the mesenchyme. (G) Radioactive in situ hybridization showing follistatin expression induced in the epithelial cells immediately adjacent to the mesenchyme. 
signals pass from the dental epithelium to the underlyingmesenchyme to stimulate tooth development. By the early bud stage (E12) the direction of interactions is reversed and signals pass from the mesenchyme to the tooth germ epithelium. The detection of activin $\beta A$ expression in presumptive tooth mesenchyme between E10.5 and E11.5 and its ability to induce follistatin expression in tooth germ epithelium suggested activin was involved in a key early mesenchyme-to-epithelium signaling event. This was investigated by transient application of activin A-soaked beads to the mesenchyme to determine whether mutant molar tooth development could be rescued. Remarkably, we found that the program of tooth devel opment could be rescued completely from E11.5 by a single activin-soaked bead, but not from E12.5 or E13.5, at which times activin beads fail to rescue progress beyond the bud stage. These experiments show clearly that activin is required for mandibular moIar tooth development before E12.5 and that if these developing teeth reach the early bud stage in the absence of activin $\beta A$, the cannot be rescued subsequently. This suggests that activin might be signaling to the epithelium at E11.5 and inducing a response that permits development to proceed to the bud stage. Therefore, if activin was signaling to the epithelium we expected wildtype E13.5 epithelium to support tooth development beyond the bud stage when recombined with activin $\beta A$ mutant mesenchyme and that no rescue would be seen with mutant epithelium, which would not have received a signal, when recombined with wild-type mesenchyme at E13.5. However, wild-type epithelium was unable to rescue tooth development, whereas the recombinations including mutant epithelium were able to rescue tooth development. These results, together with the rescue achieved by implanting activin beads at E11.5 but not at E12.5 or E13.5, lead to several possible interpretations of the mechanism of the early essential activin signaling. Either activin signals between mesenchymal cells or activin signals to the epithelium and there follows an unknown reciprocal signal back from the epithelium to the mesenchyme by E13.5, or signaling involves both mesenchyme-to-mesenchyme as well as mesenchyme-to-epithelial elements. Analysis of the expression patterns of activin receptors IIA and IIB in E11.5 embryos reveals low levels of expression in both epithelium and mesenchyme (data not shown), indicating that the activin signal can be transduced in both of these tissues.

$\mathrm{N}$ evertheless, as far as tooth development is concerned, the results obtai ned appear more consistent with an essential role for activin in mesenchymal-mesenchymal cell interactions rather than mesenchymal-epithelial cell interactions. To elaborate, epithelium from activin mutants at E13.5 is able to support tooth development when recombined with wild-type mesenchyme. Thus, if essential mesenchyme-to-epithelial signals are involved before E13.5, these signals must have no effect on the ability of epithelium to support tooth development. Moreover, it seems unlikely that such an elaborate reciprocal signaling exchange would be active with no discernible affects on the epithelium.
There is no doubt, however, that activin does signal to the epithelium at E11.5 to induce expression of follistatin. Because activin is continuously produced by tooth mesenchymal cells it needs to be continuously removed for a temporal sequence of signaling to continue to be instructive. Expression of follistatin in adjacant epithelial cells may thus act as a continuous "sink" for activin protein to remove it from the mesenchyme.

The question of whether activin plays a role in signaling to the epithelium after E13.5 in addition to its essential early signaling is not addressed by the bead rescue data. It is unlikely, however, that such late signaling is important for tooth development. We have shown that the implanted beads act as the only source of activin in the rescue experiments because exogenous activin does not cause the induction of its own expression. It is improbable, therefore, that the teeth derived from mutant explants in the bead rescue experiment at E11.5 developed because of a sustained activin signal throughout the period of culture. The stability of the activin protein in a mandible explant is difficult to assess experimentally, but it is unlikely that the activin protein diffusing from a single activin bead implanted at E11.5 could remain stable and sustain tooth development for 12 days in culture. Furthermore, because we have shown that activin $\beta A$ induces follistatin expression in the epithelium, follistatin would subsequently bind activin and further reduce its activity in the explants.

A large number of genes have been identified as being expressed at the bud stage of tooth development in either epithelial or mesenchymal cells, or both (http://www. honeybee.hel sinki.fi / toothexp). Using in situ hybridization we have shown that expression of a number of the most significant of the mesenchymally and epithelially expressed genes is unaffected in activin $\beta A$ mutant tooth germs. Thus, the expression of Msx1, Lef1, Bmp4, DIx2, and Pax9, all of which have been shown to have an essential role for tooth development, is the same in tooth bud mesenchyme of activin $\beta A$ mutant incisor and mandibular molars as in wild-type buds and the unaffected maxillary molar buds in the mutants. Therefore, at a transcriptional level, none of these genes is involved in the activin signaling pathway downstream of activin A binding to its receptors, and this expression analysis thus gives no further clue as to whether activin is signaling within the mesenchyme or via the epithelium. Clearly, activin signaling acts on as yet unidentified molecules in the odontogenic tissues, which points to the existence of a previously unidentified pathway acting within the developing teeth.

We bel ieve the simplest explanation that is consistent with the results is that activin is an essential early mesenchymal signal acting at E11.5 and before E12.5, which is required to induce changes in the mesenchyme before E13.5 so that tooth development can proceed beyond the early bud stage.

The finding that the maintenance of activin $\beta A$ expression requires signals from oral epithelium is consistent with the early instructive role of oral epithelium for tooth development. The identification of FGF8 as a fac- 
tor that is able to substitute for oral epithelium in maintaining activin expression adds activin to a growing list of genes, including Pax9, Lhx6, Lhx7, and Msx1 expressed in facial mesenchyme that are regulated by FGF8 (N eubüser et al. 1997; Grigoriou et al. 1998; Kettunen and Thesleff 1998).

\section{The role of activin in dental patterning}

There are two possible explanations for why maxillary molar teeth devel op in the absence of activin. The most obvious possibility is that activin is involved in development of all teeth and in its absence another TGF $\beta$-like signaling molecule compensates for loss of activin $\beta A$ in maxillary molar mesenchyme. The gene product of activin $\beta A$ contributes to homodimeric activin $A$, heterodimeric activin $A B$ and inhibin $A$, which are missing in the activin $\beta A$ mutants. Activin $\beta A$ could be functionally redundant for maxillary molar development with another TGF $\beta$-family member. The most likely candidates for this role would be other activin/inhi bin or TGF $\beta$-family molecules that are able to bind to activin receptors and thus activate the same downstream genes as activin. There are three pieces of evidence that suggest this is an unlikely explanation. First, activin $\beta B$ activity is unable to compensate for activin $\beta A$ within the unaffected upper molars in the mutants because in activin $\beta A / \beta B$ double-knockout mice maxillary molar development is normal (Fig. 2G). Absence of both $\beta A$ and $\beta B$ subunits abolishes all activin and inhibin activity in these mice. Second, we found that epithelial expression of the follistatin gene was down-regulated in all teeth in activin $\beta A$ mutant embryos, but expression was unaffected in some other facial tissues such as the tongue where activin $\beta A$ is not expressed (Fig. 9). Because follistatin gene expression is lost in vivo in the unaffected maxillary molars of the mutants, we conclude that it is not required for maxillary molar development. This implies that maxillary molar development would be expected to be normal in follistatin mutant mice, and examination of follistatin mutant embryos confirms this (Matzuk et al. 1995c; M. Matzuk and P.T. Sharpe, unpubl.). A role for follistatin in tooth development may only be evident in the presence of activin A because follistatin functions to inhbit activin. follistatin mutant embryos do have a weakly penetrant lower incisor development phenotype that is dependent on genetic background (Matzuk et al. 1995c). The fact that follistatin expression is downstream of activin, yet is absent from unaffected maxillary molars in the mutant, suggests that the mesenchyme-to-epithelium component of the activin signaling pathway is not activated by a compensatory molecule in the maxillary molars of mutants. This does not exclude the possibility that the mesenchymal activin pathway is activated by such a molecule. Finally, preliminary analysis of activin type IIA and IIB receptor double mutant embryos indicates that loss of these receptors can produce a similar tooth patterning phenotype to loss of activin $\beta$ A (P. Oh, E. Li, and P.T. Sharpe, unpubl.).
An alternative possibility to explain why maxillary molars are unaffected in activin $\beta A$ mutants is that de velopment of these teeth is fundamentally different from all other teeth and does not require activin. Development of maxillary molar teeth certainly appears to involve a pathway that is independent of other tooth development. Mutations in the DIX1 and DIX2 homeobox genes result in a tooth phenotype where maxillary molars fail to develop, but all other teeth develop normally (Qiu et al. 1997; Thomas et al. 1997). Thus, this phenotype is the reciprocal of the activin $\beta A$ mutant phenotype. It is possible that DLX 1 and DLX 2 may activate the same essential genes that are downstream in the activin pathway in maxillary molars, thus negating the need for activin during the development of these teeth. In turn, maxillary molar tooth development might be fundamentally different from that of all other teeth.

\section{Materials and methods}

\section{Production and analysis of mutant embryos}

activin $\beta$ A mutant and activin $\beta A / \beta B$ double mutant embryos were produced as described by Matzuk et al. (1995a) using homologous recombination in ES cells. Animals were maintained as heterozygotes and mated to generate homozygous mutant embryos. Day E0 was taken to be midnight prior to finding a vaginal plug. Embryos were harvested at the appropriate time and genotyped using PCR and Southern bl ot anal ysis of genomic DNA extracted from unused embryonic or extraembryonic tissue. The following primers were used for the PCR assays: 5'-TGATGAAAAGCCTGCTGCTGTAA-3' and 5'-CTTTCTAGACATTATTACTTGGGTTGTGCT-3', which amplified a 1.8-kb fragment containing exon 2 in wild-type and heterozygote littermates. When PCR was used, the embryos that were identified by the absence of the 1.8-kb PCR fragment were classified as potential homozygous mutants. The genotypes were then confirmed by Southern blot hybridization as described.

For basic histology embryos were fixed in $4 \%$ paraformaldehyde, wax embedded, serially sectioned, and stained with mal achite green. N ewborn mice were decalcified in $0.5 \mathrm{M}$ EDTA $(\mathrm{pH}$ 7.6) following fixation, double embedded, that is, by use of a combination of paraffin wax and nitrocellulose as embedding media according to Page (1990), serial sectioned, and stained with alcian blue/chlorontine fast red.

\section{In situ hybridization}

Radioactive in situ hybridization procedures were carried out on embryos at E10.5-E14.5 as described by Wilkinson (1995). The radioactive antisense probes used were generated from mouse CDNA clones that were gifts from several laboratories: activin $\beta A$ and follistatin (A.J.M. van den Eijnden-van Raaij, Hubrecht Laboratory, N etherlands Institute for Developmental Biology, Utrecht, The N etherlands), Barx1 (J.-F. Brunet, Developmental Biology Institute of M arseille, France), Bmp4 (B. Hogan, Vanderbilt University Medical School, Nashville, TN), Bmp7 (V. Rosen, Genetics Institute, Inc., Cambridge, MA), CD44 (C. Isacke, Imperial College of Science, Technology, and M edicine, London, UK), DIx2 (J. Rubenstein, University of California, San Fransisco), Fgf8 (I. Mason, United Medical and Dental Schools, Guy's Hospital, London, UK), Gli3 (C.C. Hui, Harvard University, Cambridge, MA), Otlx2 (C. Goridis, Developmental Biology Institute of M arseille), Pax9 (R. Balling, Institut für Säuger- 
tiergenetik, GSF-Forschungszentrum für Umwelt und Gesundheit, Neuherberg, Germany), Shh (A. MCMahon, Harvard University, Cambridge, MA), Syndecan-1 (P. Kettunen, Institute of Biotechnology, University of Helsinki, Finland), and TGF $\beta 1$ and TGF $\beta 3$ (R. D'Souza, The University of Texas, Houston).

\section{Activin bead rescue experiments}

Mandibles from embryos at E11.5, E12.5, and E13.5 were dissected in DMEM with glutamax-1 (GIBCO BRL). The rest of the embryo was used for genotyping. For cultures at E11.5 and E13.5, individual molar tooth anlagen were isolated from surrounding oral and aboral tissue, whereas for cultures at E12.5, whole mandibles were used. These were placed with oral surfaces facing upwards, on membrane filters supported by metal grids following the Trowell technique as modified by Saxén (Trowell 1959; Saxén 1966). Affi-gel agarose beads (Bio-Rad) were washed several times in PBS and then dried before being added to either recombinant activin A protein (gift from Mike Jones, NIMR, London, UK) at $1 \mu \mathrm{g} / \mathrm{ml}$, a concentration that induced mesoderm formation in Xenopus animal cap assays (not shown), or BSA at the same concentration for $1 \mathrm{hr}$ at $37^{\circ} \mathrm{C}$. The beads were pushed into the mesenchyme so that they lay in close proximity to the developing tooth germs as indicated in Figure 4A. The mandible explants at E11.5 and E13.5 were cultured with beads for $24-72 \mathrm{hr}$ in DMEM with $10 \%$ fetal calf serum (FCS). The E12.5 mandible explants were cultured with beads for 6 days, fixed in 4\% paraformal dehyde (Sigma), and processed for histological examination using hemotoxylin/eosin staining. A standard incubator was used at $37^{\circ} \mathrm{C}$ with an atmosphere of $5 \% \mathrm{CO}_{2}$ in air and $100 \%$ humidity. All solutions contained penicillin and streptomycin at $20 \mathrm{IU} / \mathrm{ml}$. After the period of culture, the E11.5 and E13.5 explants were removed from their membrane filters and transplanted under the kidney capsules of male adult mice. During this procedure, most of the beads were dissociated from the explants. The explants were cultured in host kidneys for 10 days to allow for full development of teeth. The resulting tissues were then fixed in Bouin's solution (Sigma), dehydrated, and embedded. Serial sections of 7 $\mu \mathrm{m}$ were cut and stained using al cian blue/chlorontine fast red.

\section{Epithelial-mesenchymal tissue recombinations}

Recombinations were carried out at E11.5 and E13.5. Molar anlagen of the mandibles were dissected out in DMEM with glutamax-1. The epithelium and mesenchyme were isolated following incubation in a solution of dispase (GIBCO BRL) made up in calcium- and magnesium-free PBS at $2 \mathrm{U} / \mathrm{ml}$ for $10-15$ $\min$ at $37^{\circ} \mathrm{C}$. After incubation the mandibles were washed in DMEM with $10 \%$ FCS, and the tissues were mechanically separated using fine tungsten needles. For recombination, epithelium and mesenchyme were aligned in the correct orientation (as in Fig. 6A) on top of transparent $\mathrm{N} \mathrm{ucl} \mathrm{epore} \mathrm{membrane} \mathrm{filters}$ (0.1- $\mu \mathrm{m}$-pore diameter; Costar). The recombinations were cultured for 24-48 hr in DMEM with 10\% FCS, after which they were either fixed and processed for radioactive in situ hybridization, or transplanted under the kidney capsule of male adult mice and cultured for a further 10 days to allow for full development of teeth.

\section{FGF8/BMP4 bead experiments}

$M$ andibles were dissected at E11.5. Where indicated, epithel ium was removed after incubation in dispase $(2 \mathrm{U} / \mathrm{ml})$ for $10 \mathrm{~min}$ at $37^{\circ} \mathrm{C}$. For the application of FGF8 protein, heparin acrylic beads
(Sigma) were washed and then incubated overnight in $1 \mathrm{mg} / \mathrm{ml}$ FGF8 protein (recombinant mouse FGF8b; R\&D Systems, A bingdon, UK) at $4^{\circ} \mathrm{C}$. For the application of BMP4 protein, Affi-gel agarose beads were washed and soaked in the protein (recombinant human BMP4; gift from the Genetics Institute, Cambridge, MA) for $1 \mathrm{hr}$ at $37^{\circ} \mathrm{C}$. A concentration of $100 \mu \mathrm{g} / \mu \mathrm{l}$ BM P4 was used, as this concentration has been shown to inhibit Pax9 expression in a similar assay ( $N$ eubüser et al. 1997). After 24-48 hr in culture the explants were fixed and processed for in situ hybridization. Digoxygenin (DIG) whole-mount in situ hybridization was carried out as described by Pownall et al. (1996).

\section{Epithelial cultures}

Oral epithelium was isolated after incubation of E11.5 mandibles in Dispase $(2 \mathrm{U} / \mathrm{ml})$ for $10 \mathrm{~min}$ at $37^{\circ} \mathrm{C}$. The epithelium was cultured in Matrigel (Collaborative Biomedical Products) on membrane filters supported by metal grids as described above and indicated in Figure 10A. Matrigel is a solubilized basement membrane extracted from the Engel breth-HolmSwarm mouse sarcoma cell line and provides a matrix in which epithelial cells can devel op. The gel sets rapidly and irreversibly at temperatures between $22^{\circ} \mathrm{C}$ and $35^{\circ} \mathrm{C}$. Therefore, the product must be kept on ice and precooled pipettes used. The filters were covered with $\mathrm{M}$ atrigel and set at $37^{\circ} \mathrm{C}$ before the epithelia were pipetted on top. To visualize the epithelia they were weakly dyed with neutral red before being placed onto the $\mathrm{Ma}$ trigel. Affi-gel agarose beads (Bio-Rad) soaked in recombinant activin A protein $(1 \mathrm{mg} / \mathrm{ml})$ or BSA were prepared as described above. Beads were placed on top of the epithelia, which were then topped with more $M$ atrigel so that the cultures were surrounded. The epithelia with beads were cultured for $48 \mathrm{hr}$ in DMEM with $10 \%$ FCS. Cultures were washed in ice-cold methanol for $1 \mathrm{~min}$ and fixed in fresh $4 \%$ paraformal dehyde for $1 \mathrm{hr}$ at room temperature. Cultures were then prepared for ${ }^{35} \mathrm{~S}$ section in situ hybridization.

\section{Acknowledgments}

This research was funded by grants from the M edical Research Council and the Human Frontier Science Program Organization (to P.T.S.) and from the $\mathrm{N}$ ational Institutes of Health (grant HD32067 to M.M.M.). A.L.L. is supported by the N ational Science Foundation Developmental Biology Training grant BIR9413237. We thank Bethan Thomas for critical reading of the manuscript, Klaus Kratochwil for teaching us the kidney capsule culture technique, and $\mathrm{En} \mathrm{Li}$ and Paul Oh for allowing us to quote unpublished results.

The publication costs of this article were defrayed in part by payment of page charges. This article must therefore be hereby marked "advertisement" in accordance with 18 USC section 1734 solely to indicate this fact.

\section{References}

Åberg, T., J. Wozney, and I. Thesl eff. 1997. Expression patterns of BM Ps in the devel oping mouse tooth suggest roles in morphogenesis and cell differentiation. Dev. Dyn. 210: 383-396. Asashima, M., H. N akano, K. Shimada, K. Kinoshita, K. Ishii, H. Shibai, and N. Ueno. 1990. Mesodermal induction in early amphibian embryos by activin A (erythroid differentiation factor). Wilhelm Roux's Arch. Dev. Biol. 198: 330-335.

Bitgood, M.J. and, A.P. McMahon. 1995. Hedgehog and Bmp genes are coexpressed at many diverse sites of cell-cell interaction in the mouse embryo. Dev. Biol. 172: 126-138. 
Chai, Y., A. Mah, C. Crohin, S. Groff, P. Bringas, Jr., T. Le, V. Santos, and H.C. Slavkin. 1994. Specific transforming growth factor- $\beta$ subtypes regulate embryonic mouse M eckel's cartilage and tooth devel opment. Dev. Biol. 162: 85-103.

Chen, Y., M. Bei, I. Woo, I. Satokata, and R. M aas. 1996. M sx1 controls inductive signalling in mammalian tooth morphogenesis. Development 122: 3035-3044.

Conlon, F. 1994. A primary requirement for $\mathrm{N}$ odal in the formation and maintenance of the primitive streak in the mouse. Development 120: 1919-1928.

Crossley, P.H. and G.R. Martin. 1995. The mouse Fgf8 gene encodes a family of polypeptides and is expressed in regions that direct outgrowth and patterning in the developing embryo. Development 121: 439-451.

De Winter, J.P., P. Ten Dijke, C.J.M. De Vries, T.A.E. Van Acterberg, P. De Waele, D. Huylebroeck, K. Verschueren, and A.J.M. van den Eijnden-van Raaij. 1996. Follistatins neutralise activin bioactivity by inhibition of activin binding to its type II receptors. Mol. Cell Endocrinol. 116: 105-114.

Dohrmann, C.E., A. Hemmati-Brivanlou, G.H. Thomsen, and A. Fields. 1993. Expression of activin mRNA during early development in Xenopus laevis. Dev. Biol. 157: 474-483.

Dyson, S. and J.B. Gurdon. 1997. Activin signalling has a necessary function in Xenopus early development. Curr. Biol. 7: 81-84.

Feijen, A., M.J. Goumans, and A.J.M . van den Eijnden-van Raaij. 1994. Expression of activin subunits, activin receptors and follistatin in postimplantation mouse embryos suggests specific developmental functions for different activins. Development 120: 3621-3637.

Green, J.B.A. and J.C. Smith. 1990. Graded changes in dose of a Xenopus activin A homolog elicit stepwise transitions in embryonic cell fate. Nature 347: 391-394.

Green, J.B.A., H.V. N ew, and J.C. Smith. 1992. Responses of embryonic Xenopus cells to activin and FGF are separated by multiple dose thresholds and correspond to distinct axes of the mesoderm. Cell 71: 731-739.

Grigoriou, M., A.S. Tucker, P.T. Sharpe, and V. Pachnis. 1998. Expression and regulation of Lhx6 and Lhx7, a novel subfamily of LIM homeodomain encoding genes, suggests a role in mammalian head development. Development 125: 20632074.

Hardcastle, Z., R. Mo, C.-C. Hui, and P.T. Sharpe. 1998. The Shh signalling pathway in tooth development: Defects in Gli2 and Gli3 mutants. Devel opment 125: 2803-2811.

Heikinheimo, K., C. Bègue-Kirn, O. Ritvos, T. Tuuri, and J.V. Ruch. 1997. The activin-binding protein follistatin is expressed in developing murine molar and induces odontoblast-like cell differentiation in vitro. J. Dent. Res. 76: 16251636.

Heikinheimo, M., A. Lawshe, G.M. Shackleford, D.B. Wilson, and C.A. MacArthur. 1994. Fgf-8 expression in the post-gastrulation mouse suggests roles in the development of the face, limbs and central nervous system. Mech. Dev. 48: 129138.

Hemmati-Brivanlou, A. and D.A. Melton. 1992. A truncated activin receptor dominantly inhibits mesoderm induction and formation of axial structures in Xenopus embryos. Nature 359: 609-614.

- - - 1994. Inhibition of activin receptor signalling promotes neuralization in Xenopus. Cell 77: 273-281.

Hemmati-Brivanlou, A., O.G. Kelly, and D.A. Melton. 1994. Follistatin, an antagonist of activin, is expressed in the Spe mann Organiser and displays di rect neural izing activity. Cell 77: 283-295.

Iseki, S., A. Araga, H. Ohuchi, T. N ohno, H. Yoshioka, F. Haya- shi, and S. Noji. 1996. Sonic hedgehog is expressed in epithelial cells during development of whisker, hair, and tooth. Biochem. Biophys. Res. Commun. 218: 688-693.

Kettunen, P. and I. Thesl eff. 1998. Expression and function of FGFs-4, -8, and -9 suggest functional redundancy and repetitive use as epithelial signalls during tooth morphogenesis. Dev. Dyn. 211: 256-268.

Kollar, E.J. and G.R. Baird. 1969. The influence of the dental papilla on the development of tooth shape in embryonic mouse tooth germs. J. Embryol. Exp. Morph. 21: 131-148.

Kratochwil, K., M. Dull, I. Fariñas, J. Galceran, and R. Grosschedl. 1996. Lef1 expression is activated by BM P-4 and regulates inductive tissue interactions in tooth and hair development. Genes \& Dev. 10: 1382-1394.

Lumsden, A.G. 1988. Spatial organization of the epithelium and the role of neural crest cells in the initiation of the mammalian tooth germ. Development 103: 155-169.

Mackenzie, A., G.L. Leeming, A.K. Jowett, M.W.J. Ferguson, and P.T. Sharpe. 1991. The homeobox gene Hox-7.1 has specific regional and temporal expression patterns during early murine craniofacial embryogenesis, especially tooth development in vivo and in vitro. Development 111: 269-285.

Matzuk, M.M., T.R. Kumar, A. Vassalli, J.R. Bickenbach, D.R. Roop, R. Jaenisch, and A. Bradl ey. 1995a. Functional analysis of activins during mammalian development. Nature 374: 354-356.

Matzuk, M.M., T.R. Kumar, and A. Bradley. 1995b. Different phenotypes for mice deficient in either activins or activin receptor type II. Nature 374: 356-360.

Matzuk, M.M., N. Lu, H. Vogel, K. Selheyer, D.R. Roop, and A. Bradley. 1995c. Multiple defects and perinatal death in mice deficient in follistatin. Nature 374: 360-363.

Michel, U., P. Farnworth, and J.P. Finlay. 1993. Follistatins: more than follicle-stimulating hormone suppressing proteins. Mol. Cell Endocrinol. 91: 1-11.

Mina, M. and E.J. Kollar. 1987. The induction of odontogenesis in non-dental mesenchyme combined with early murine mandibular arch epithelium. Arch. Oral. Biol. 32: 123-127.

Mucchielli, M., T.A. Mitsiadis, S. Raffo, J. Brunet, J. Proust, and C. Goridis. 1997. Mouse Otlx2/RIEG expression in the odontogenic epithelium precedes tooth initiation and requires mesenchymal derived signalls for its maintenance. Dev. Biol. 189: 275-284.

N akamura, T., K. Takio, Y. Eto, H. Shibai, K. Titani, and H. Sugino. 1990. Activin-binding protein from rat ovary is follistatin. Science 247: 836-838.

N eubüser, A., H. Peters, R. Balling, and G.R. Martin. 1997. Antagonistic interactions between FGF and BMP signalling pathways: A mechanism for positioning the sites of tooth formation. Cell 90: 247-255.

Page, K.M. 1990. Bone. In Theory and practice of histological techniques, 3rd ed. (ed. J.D. Bancroft and A. Stevens), pp. 309-341. Churchill Livingstone, Edinburgh, UK.

Pownall, M.E., A.S. Tucker, J.M.W. Slack, and H.V. Isaacs. 1996. eFGF, Xcad3 and Hox genes form a molecular pathway that establishes the anteroposterior axis in Xenopus. Development 122: 3881-3892.

Qiu, M., A. Bufone, I. Ghattas, J.J. Menses, P.T. Sharpe, R. Presley, R.A. Pedersen, and J.L.R. Rubenstein. 1997. Role of DIx-1 and -2 in proximodistal patterning of the branchial arches: mutations alter morphogenesis of proximal skel etal el ements derived from the first and second branchial arches. Dev. Biol. 185: 165-184.

Roberts, V.J. and S.L. Barth. 1994. Expression of messenger ribonucleic acids encoding the inhibin/activin system during mid- and late-gestation rat embryogenesis. Endocrinology 
128: 914-923.

Roberts, V.J., P.E. Sawchenko, and W.W. Vale. 1991. Expression of inhibin/activin subunit messenger ribonucleic acids during rat embryogenesis. Endocrinology 128: 3122-3129.

Saxén, L. 1966. The effect of tetracyclin on osteogenesis in vitro. J. Exp. Zool. 162: 269-294.

Satokata, I. and R. Maas. 1994. Msx-1 deficient mice exhibit cleft palate and abnormalities of craniofacial and tooth development. Nature Genet. 6: 348-356.

Semina, E.V., R. Reiter, N.J. Leysens, W.L. Alward, K.W. Small, N.A. Datson, J. Siegel-Bartelt, D. Bierke-N elson, P. Bitoun, B.U. Zabel, J.C. Carey, and J.C. Murray. 1996. Cloning and characterization of a novel bicoid-related homeobox transcription factor gene, RIEG, involved in Rieger syndrome. Nature Genet. 14: 392-399.

Thesleff, I. and P.T. Sharpe. 1997. Signalling networks regulating dental development. Mech. Dev. 67: 111-123.

Thesleff, I., A. Vaahtokari, and A.-M. Partanen. 1995. Regulation of organogenesis. Common molecular mechanisms regulating the devel opment of teeth and other organs. Int. J. Dev. Biol. 39: 35-50.

Thesleff, I., A. Vaahtokari, S. Vainio, and A. Jowett. 1996. Molecular mechanisms of cell and tissue interactions during early tooth development. Anat. Rec. 245: 151-161.

Thomas, B.L., M.H. Porteus, J.L.R. Rubenstein, and P.T. Sharpe. 1995. The spatial localization of DIx-2 during tooth development. Connect. Tissue Res. 32: 27-34.

Thomas, B.L., A.S. Tucker, M. Qui, C.A. Ferguson, Z. Hardcastle, J.L.R. Rubenstein, and P.T. Sharpe. 1997. Role of DIx-1 and DIx-2 genes in patterning of the murine dentition. Development 124: 4811-4818.

Thomsen, G., T. Woolf, M. Whitman, S. Sokol, J. Vaughan, W. Vale, and D.A. M elton. 1990. Activins are expressed early in Xenopus embryogenesis and can induce axial mesoderm and anterior structures. Cell 63: 485-493.

Tissier-Seta, J.P., M.L. Mucchielli, M. Mark, M.G. Mattei, C. Goridis, and J.F. Brunet. 1995. Barx1, a new mouse homeodomain transcription factor expressed in cranio-facial ectomesenchyme and the stomach. Mech. Dev. 51: 3-15.

Trowell, O.A. 1959. The culture of mature organs in a synthetic medium. Exp. Cell Res. 16: 118-147.

Vaahtokari, A., S. Vainio, and I. Thesleff. 1991. Associations between transforming growth factor beta 1 RN A expression and epithelial-mesenchymal interactions during tooth morphogenesis. Development 113: 985-994.

Vaahtokari, A., T. Å berg, J. Jernvall, S. Keranen, and I. Thesl eff. 1996. The enamel knot as a signalling center in the developing mouse tooth. Mech. Dev. 54: 39-43.

Vainio, S., I. Karavanova, A. Jowett, and I. Thesleff. 1993. Identification of BMP-4 as a signal mediating secondary induction between epithelial and mesenchymal tissues during early tooth development. Cell 75: 45-58.

Vale, W.W., A. Hseuh, C. Rivier, and J. Yu. 1990. The inhibin/ activin family of hormones and growth factors. In Peptide growth factors and their receptors II (ed. M.B. Sporn and A.B. Roberts), pp. 211-248. Springer-Verlag, Berlin, Germany.

van Genderen, C., R.M. Okamura, I. Fariñas, R.G. Quo, T.G. Parslow, L. Bruhn, and R. Grosschedl. 1994. Devel opment of several organs that require inductive epithelial-mesenchymal interactions is impaired in LEF-1-deficient mice. Genes \& Dev. 8: 2691-2703.

Wheatley, S.C., C.M. Isacke, and P.H. Crossley. 1993. Restricted expression of the hyaluronan receptor, CD44, during postimplantation mouse embryogenesis suggests key roles in tissue formation and patterning. Development 119: 295306.
Wilkinson, D.G. 1995. In situ hybridization, a practical approach. IRL Press, Oxford, UK.

Zhou, X., H. Sasaki, L. Lowe, B.L.M. Hogan, and M.R. Kuehn. 1993. Nodal is a novel TGF $\beta$-like gene expressed in the mouse node during gastrulation. Nature 361: 543-547. 


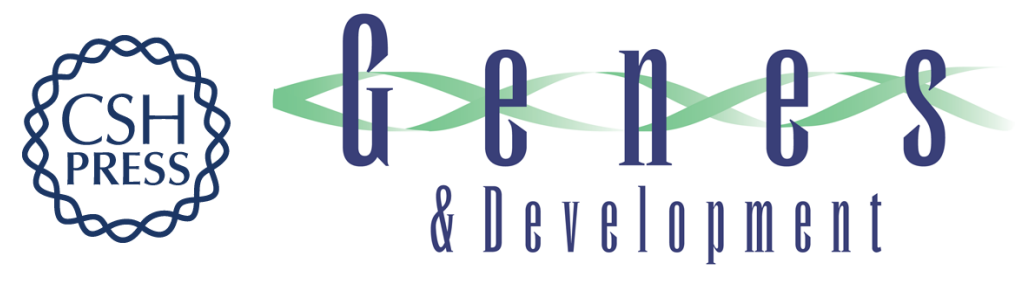

\section{Activin is an essential early mesenchymal signal in tooth development that is required for patterning of the murine dentition}

Christine A. Ferguson, Abigail S. Tucker, Lars Christensen, et al.

Genes Dev. 1998, 12:

Access the most recent version at doi:10.1101/gad.12.16.2636

References

This article cites 53 articles, 14 of which can be accessed free at: http://genesdev.cshlp.org/content/12/16/2636.full.html\#ref-list-1

License

Email Alerting

Receive free email alerts when new articles cite this article - sign up in the box at the top Service right corner of the article or click here.

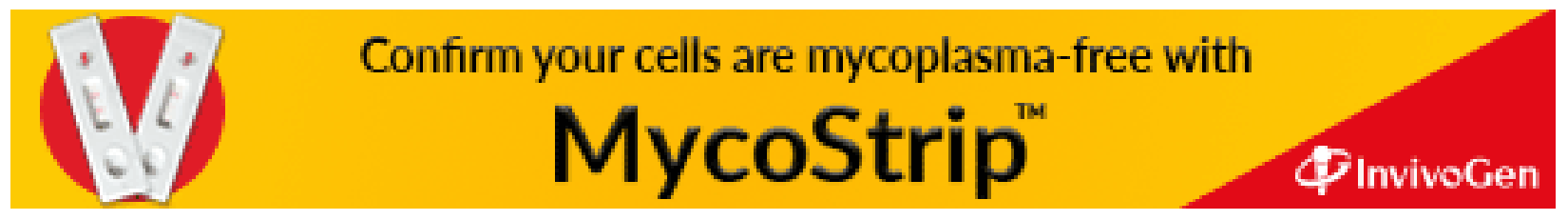

